\title{
Fiscal Policy, Taxes and Their Impact on Economic Development
}

\author{
Malush Krasniqi, PhD.c. \\ Ministry of Finance, Tax Administration, Audit Team Leader \\ Dep. Operations - Team Controls, Prizren, Kossovo \\ malush.krasniqi@atk-ks.org, malushi07@hotmail.com
}

\section{Doi:10.5901/ajis.2013.v2n8p463}

\begin{abstract}
The paper presents comparisons of fiscal policy - tax amongst different countries. Many developed countries and developing countries have used fiscal policy Tax-oriented to develop the economy. Taxes transition in the Western Balkan countries is oriented reforms modeled according to three main priorities: 1- Simplification of the tax system, 2- Establish transparency and clear procedures and 3- Safety that the legislation has being implemented fairly. Increasing taxes is intended to increase budget revenues can often be self-defeating and that public authorities should limit contributions to social insurance funds in order to stimulate job creation and development of small and medium. At the same time, some transition countries have embraced fiscal policy as a potential tool for attracting foreign direct investments in the country. Taxes (fiscal policy) have their importance to the need for improved the projected benefits of the field in stimulating and building profitable economic sectors. States through the tax impact on attracting foreign investment and increase employment of the population as is the case of Slovakia in attracting Hyundai to invest offering low taxes and the tax holiday period. Tax legislation is such an area. A second perspective about the ability of governments is to use taxes in order to encourage more business. Some new countries acceding EU taxes are reduced to a level such that the older members are talking about "unfair competition". The case of Slovakia has established a single quote for income tax (19\%) mimicking the pattern in which the Baltic countries have experimented for years. Corporate taxes are also lower in countries such as Poland and Hungary. Another example Austria, has decided to develop similar policies in order to stem a possible removal of the capital. Although national fiscal policies represent a wide range of variation within the EU. European Union and competitive area best in the world in terms of knowledge-based economy reinforces this fear (capital flight). It may be only a matter of time before the European Commission in Brussels to deal with the definition of "rules" intended to administer tax competition within the EU.
\end{abstract}

Keywords: fiscal policies, taxation, economic development, tax comparisons.

\section{Introduction}

\subsection{Purpose of the study}

The purpose of this study is to present the impact of "fiscal policy - taxes on economic development" (Kosovo case) this idea has come to our everyday motif and its direct and indirect impact on our society and in our vicinity. The importance of fiscal policy affects economic development and orientation of a country, stimulates the development of local business and attracting investors made different from the outside. But when economic development are important is the implementation or application of these policies in practice by eliminating various bureaucracies of the unnecessary, using the lower tax rate and providing reassurance to capital investors, creating facilities for arranging the necessary documentation for business etc. Switching systems from a centralized economy to a free market economy or phase transitions in many countries of Europe and the world have shown that there are difficulties with which their faces almost every society in transition. However, in those countries where state or government reacted quickly to establish fiscal policies, sound development policy stimulus phase transition has been easier and more efficient control and has been given the expected results. The awareness of the population to be repaid various obligations to the state, the development of small and medium enterprises in the employment of population decrease extreme poverty where are delayed while these policies have continued problems and poverty is increasing.

Therefore, taking into account the economic circumstances fiscal policy and the development of market economy in our country have made the selection of this topic in order to give my contribution to this discussion topic.

The economic development of a country or society based on the experience of economically developed countries and developing ones, has shown that for the market to develop the economy should be compiled and implemented fiscal 
policies favorable to business in order to attract investment and creating investment security.( Komoni, 2008). The key question is how to develop the country approaching favorable fiscal policies and developmental? Methodology- that I will use to give answer to this question is to compare the tax rates of the developed countries and those in developing compared with tax rates in Kosovo. The paper will be divided into two parts: The first part will explain, 1) fiscal policy in some countries, their tax rates as countries with economies former centralized system, and now with open market economy, what tax rates are used to develop their country and have attracted foreign investors to invest in their country? 2) The role and purpose of fiscal policy in economic development of a country, the second part of this theme will address the transition in Kosovo from 1999 to 2010(Nimani, 2010).

Challenges in developing state-of Global Economic Developments (Civici 2012, Salman, 2006) (objectives and policies) (Squirrel 2008).

\subsection{Fiscal policy in countries with economies in transition}

Bearing in mind that we said above, in various European countries and the Balkan can often say that the country's fiscal policies have developed the site or have hindered economic development (the former socialist countries with planned economies or centralized). Now, I will present some examples of some countries which have made major reforms and successful in economic development. Countries like Poland, the Czech Republic, Slovenia, Hungary, Lithuania and similar, have been more successful in reforming the tax system and tax administration have a more advanced legitimacy that enables efficient implementation of tax laws and have reached a higher degree of economic development, which offered approximately Western European countries (Artan Nimani ,2010,p,44). Transition countries have followed different paths in the selection of the tax structure and the importance given to a particular tax. Countries with more advanced and better-prepared tax administration, tax system have selected that resembles EU countries. This comes because of the efforts of these countries to meet the basic principles of the EU and the harmonization of the tax system with that of the EU. Another example, Poland since June 1993, turnover tax was replaced with VAT where the VAT law allows three tax rate: $22 \%, 7 \%$ and $0 \%$. On acquisition of enterprises paid taxes of $40 \%$, which provided certain relief for those enterprises realized profits to re-invest. In personal income tax, apply three tax rates: $21 \%, 33 \%$ and $45 \%$ depending on the level of revenue try to realize these are good examples of practice and taking as a model in case of need, and if they have access to practical development in these countries, to be implemented and to us. Also, apply different excise on fuel, alcoholic beverages, tobacco, weapons, vehicles, ships, electrical goods, etc. Another example in the Czech Republic, face the same taxes, which differ only in their scales. Profit tax rate is $35 \%$ and the reduced rate of $25 \%$, which applies to profits from the basic pension and investment funds for income derived from the distribution of profits. Personal incomes, depending on their level of yearly, apply the tax rate: $15 \%, 20 \%, 25 \%, 32 \%$ and $40 \%$. VAT has 2 steps, $22 \%$ for goods, $5 \%$ for services. In Bulgaria, the profit tax, the enterprise has two levels $27 \%$ and $20 \%$, where the reduced rate applies to those companies that have lower profit than 25,000 Euro. Local tax rate is $10 \%$. Personal income tax is scalable, depending on annual income level is: $0 \%, 20 \%, 26 \%, 32 \%$ and $40 \%$. The main burden of social insurance contributions, employers keep paying wages $34.7 \%$, while employees pay only $1 \%$. Employers also pay $3.5 \%$ in the unemployment fund. In Bulgaria since 1999, VAT applies to the unique degree of $20 \%$, excluding gold imports made only by central banks taxed at a rate of $0 \%$.

In Croatia, is introduced VAT with a single rate of $22 \%$ with the exception only of some goods like bread, milk, literature, some herbs, plants similar to that applied rate 0\%(Artan Nimani, 2010 p44,45,46).

In Albania, the tax applies to companies with large profit of $30 \%$, except where tourism rate is $40 \%$ and companies that exploit oil and gas which pay 50\%. In Albania, characteristic are numerous exemptions and exceptions for investment in productive sectors. Personal income tax is scalable depending on annual income level and varies from $0 \%$, $5 \%, 10 \%, 15 \%$ and $20 \%$. Contributions to social and health insurance paid by the employer as (32.5\% and $1.7 \%)$ and the employee (10\% and 1.7\%), while the value added tax (VAT) is $20 \%$.. Viewing practices of various countries where we have some interesting hypotheses as low tax rates, to tax breaks as is the case with Slovakia which the above mentioned where unless you use single rate of tax of $19 \%$ using the policies tax break. Slovakia is a good example where the competition is very strong with the developed countries such as: Germany, Austria, etc. Hyundai investment gain. Kosovo started from the region has lower taxes where VAT rate is at $16 \%$, whereas in corporate tax rate is $10 \%$ in tax, we pay 0\%, 4\% to 8\%, 5\% employer pension contributions $5 \%$ employee, 10\% tax on rent, etc., (Sabahudin Komoni 2008,p129). But it was in Kosovo and in Albania can say is problematic still is the safety of law enforcement impartial what affects inhibit the growth of foreign investment to investors. (Nr.03/L-22 Law, 2011) 


\subsection{Fiscal policy, their role and purpose}

Given the literature but also general knowledge know that the leadership role of the state in economic fiscal policy is undisputed, the orientation of economic development, the implementation of market stability and prices, employment, the preservation of equilibrium of the balance of payments and the implementation of certain degree of economic growth and development. In the context of economic policy, fiscal policy is one of the most important components. Policy determined by the principles under which any action must be guided, as the measures and means to achieve certain goals. Economic Policy, examines the economic processes, instruments, measures and decisions of the government to realize its goals.

State or local authorities are carriers of economic policy that affect the selection and orientation as well as its implementation. These state or municipal authorities define different forms of regulation and knowingly in the direction of economic processes (Komoni, 2010). During the process of setting economic policy should first set its goals.

As key economic policy purposes, we can list these:

$>$ Full employment,

$>$ Price stability

Adjusting the balance of payments,

$>$ Expansion of production - economic growth,

$>$ Allocations

- The allocation of factors of production (including the promotion of domestic competition, coordination, increase their workforce and mobilizing capital in the country, as well as promoting international division of labor),

- Satisfying public needs (administrations, defense, education, culture, science, health, etc.).

The greater the number of goals and their full implementation is difficult. Based on reports, divide among themselves the goals of the purposes of independent, complementary and conflicting. Very few economic policy purposes are independent among themselves, so that the realization of an intention not to affect performance of another. Economic policy goals are complementary to the realization of a goal affects the achievement of another goal. Conflicting goals of economic policy are whether the realization of a goal makes it difficult or hinders the achievement of another goal. To realize the goals of economic policy tools used certain instruments respectively with the help of which goals are realized.

Economic policy instruments are usually classified into the following groups:

- Public finance instruments (fiscal policy)

- Instruments of monetary-credit policy;

- Instruments of the system and price policy

- Instruments of foreign trade and foreign exchange system,

- Instruments of the system and revenue policy and

- The instruments of direct control

Reconciliation between the goals of these instruments is an important process for the formulation and implementation of economic policy. With fiscal policy usually means the use of public finance instruments viz. public revenues and expenditures (expenses) for the realization of public goals of economic policy. Therefore, fiscal policy is an important instrument of economic policy. Fiscal policy affects the realization of economic policy (in employment, price stability, balance of payments and economic growth rate) on the fact of its revenue collection and public expenditure to (expenditure) public, whereby creates effects on aggregate economic performance and the behavior of economic entities. The mechanism of action of fiscal policy has to do with its long-term effects as its impact on development and faster economic growth. The function of the state is increasingly done as intermediaries in economic development, which should take care to establish general conditions for maintaining the speed of growth, and economic development. Instead of set development priorities of any sector or branch of activity, the state today is taken by upgrading basic infrastructure, with the guidance of industrial policy, regional development policy and the development of science and education as an important factor of development leading to increased competitiveness of the economy integrated into the international market (globalization). The rate of development of the economy of the state is determined by the quantity and quality of human and material resources and to achieve the level of technical and technological development. Fiscal policy therefore affects the rate of economic growth accelerated as instruments of public revenue and public expenditure can influence factors high. (Sabahudin Komoni 2008, p,16,17,18). 


\section{Fiscal Policy - Transition in Kosovo}

Given the new configuration of economic, regional, European and international, as well as the specific conditions of the construction of the economic system in Kosovo should be based on:

- Privatization of enterprises, public and social;

- Economic liberalization;

- Economic Adjustment under the concept of an open market economy;

- Principles of the rule of law;

- Social Justice;

- Orientation towards the globalization of the economy

Kosovo, as a small country at the same time as the geographical part of Europe, will be directed to the construction of the economy according to an open economy, to the European market, regional and international, with a policy of economic liberalization and regulatory measure neighborhood. Kosovo needs an economic system that creates an environment for the integration of the economy on the region and beyond, stimulating economic cooperation incentive interest in joint investments with foreign partners. (Artan Nimani, 2010, p,48).

Need clearly defined strategy, the transformation of state property (social) and private property for the development of entrepreneurship as a development philosophy in its entire necessary infrastructure. This enables the creation of a favorable environment for the development of competition and the autonomy of enterprises, including risk category.

The role of the state of Kosovo should specifically focus on contemporary macro-economic regulation to ensure economic stability and building development policy. These include: stabilization of the national currency (Euro) exchange rate, regulation of economic relations with the outside world, construction of regional policy, and construction of agricultural policy, what ecological and public finances. Macroeconomic policies of democratic governments aim to achieve four key macroeconomic objectives:

1. To ensure high rates of sustainable economic growth

2. To minimize unemployment

3. To ensure price stability and

4. To expand and strengthen international economic relations (Squirrel, 2008)

Its functioning economic system must support democratic institutions, liberal democracy and open society, and the internationalization of the economy and society.

Transition is a process known deep transformative dimensions of a social system, through which the system passes into a new facility, which provides an efficient and effective higher.

To achieve these performances, solidifying should stimulate changes in all subsystems of the social system, and above all in the political system, economic system and the education system as one of the most enduring investment development of a country.

The transition process cannot be governed by case basis. This means that the strategy needed to build the mechanisms by which these obstacles must be overcome.

On the specifics of transition in Kosovo:

a. Kosovo has experienced a very tough transition because of the 1998-1999 Kosovo war leaves with a degree in economics to destroy over $90 \%$ in terms of social enterprises, and public. However, few private enterprises which had started activities them in 1989, and over 90\% of households, based on the law to the former Yugoslavia where's that then allowed the exercise and development of business and manufacturing operations in Kosovo.

b. After the war in Kosovo from 1999 to 2008 led by the United Nations mission (UNMIK was) Kosovo is not possible to implement fiscal policies based on the principles of free market and especially because until 2005 favored imports from out and not favored internal production. In addition, what was the largest anomaly was that local products to neighboring countries such as Macedonia were, and Union, Serbia and Montenegro, was allowed to imported duty-free goods in Kosovo, namely $1 \%$ load customs, calling upon the area of free trade preferential foreign whereby priority was given to member States of the set of states of the former Yugoslavia's. In this way UNMIK with or without aim or purpose has severely damaged the economy of Kosovo but was rejected by many experts of the economy in Kosovo were not taken into account criticisms, this injustice which used the neighboring Macedonia also issue certificates for Banana, allegedly were local products, in order to enter free of duty in Kosovo.

c. Kosovo cannot be authentic enforce business policies and the fact that no national value of using the euro as 
the national currency crises thus imported from the euro area (Limani, 2008).

Fiscal policy is one of the most important components of economic policy, where at least exist two basic reasons:

1. Political economic criteria defines goals and fiscal policy

2. Explains the process of realization of economic policy, which is part of the fiscal policy itself. Well fiscal and economic policies are closely interrelated with one another (Brajshori, 2010). Transition in Kosovo started in the late 80 s, i.e. the movement for freedom and democracy.

Approximately 25\% of Kosovo's populations are in Western Europe and the U.S., the majority without status was regulated but a strong pillar of survival and war horns processes. Kosovo has now opened the doors to get out of the prolonged transition that was not active against the view that ours right to move progressively integrating these doors that open development horizons of development and improvement of social and economic life, bring best of direct investment capital with justice in Kosovo.

We should be as unique hospitality host to foreign investors, have clear short-term and medium-term policies to attract these investors build and strengthen as much state building, strengthen investment in justice and in preparation to the experts suckling economic purpose of foreign investors for the benefit of the country and the region. A capacity building opportunities we can have and invest together with our friends who have inters to be aligned development policies in the Western Balkans region. Where these investments should be seen as vital and attractive place for people and Kosovo. We must look more open to adaptation and acceptance of regional and European policies to be closer to the global international journeys. (Artan Nimani 2010, p48,50)

\subsection{Fiscal policy and challenges in developing state}

Fiscal policies dealing mainly with tax, various taxes and government spending, which directly affect the size of the gross national product, but also the living standards of citizens (Squirrel, 2008). European economies, which are more developed, compared with Kosovo force us to have caution about the economy and its orientation facing the challenges of the free market (global).

Globalization and global market is developing in many cases, the hardening of production, exchange, communication and development in general. For this reason, integration is a central issue today in contemporary international relations. (Citation: benefit from international trade is more efficient employment of the productive forces the world. -John Stuart Mill). functional aspects of international relations, such as: globalization of exchange, environmental protection, communication, etc. are still formally dependent on the process of establishing states although they mainly adopt decisions in the international format. Referring to these as discussed above some countries reluctant in taking the country in the global market or the global economy because that's what the classical form of waste being independent or sovereign state in the country. In addition, many local businesses fail because of the inability to adapt to the global market, so we can say that globalization has its positive sides but also has downsides.

Crises that shook the world is like that of 2008, based on forecasts of key international institutions for the period 2009-2011 was all seem convinced that our planet has entered into a global crisis, which has six specifications: the financial crisis, monetary, economic, food, energy and ecological. Crisis, which has genesis in the year 2007 as the financial crisis, that had originated from bad loans in the U.S. real estate market. (Civic 2012)

Viewing these detailed above we see that globalization is inevitable with the benefits and consequences of his own. Rapid changes of transition and transformation in Europe today in the international plan noted as difficult phenomenon to new states in the global economy, especially the post-socialist countries. Therefore, the creation of new global circumstances, the role of governments is to create new contexts more attractive for business and attraction of capital, in order to promote investment (Selman, 2006)

In the terminology of political economy is a difference between, quantitative economic policy and structural economic policies. Quantitative policies are policies aimed at controlling short-term economic cycles through quantitative interventions, fiscal incentives (reduction or increase of taxes and / or government spending), and increase or decrease the rate of interest, intervention by monetary policy, in other words, policy aimed at orienting the economy in one or another direction through the management of macroeconomic parameters. These are policies that in most cases the common concern of economists and fiscal state bureaucracy (as ministries of finance or central bank), or even politicians opposing ideological orientations that express the need for measures of one kind or another. These groups often finds in dealing with economic problems dealing with the need for policies and the effects of this kind: for example, provided arguments for the need to reduce taxes on businesses, in order to encourage investment, the need to stimulate demand through increased public spending; debates on reducing or increasing VAT or excise or tax rates etc.. At the foundation 
is the debate revolves entirely around the use of existing mechanisms in response to macroeconomic cyclical economic developments.

Structural economic policies are substantially different from this kind of policy. Obviously, the economy advanced and complex, e.g. what is Western Europe or the U.S., the political debate focuses mainly on quantitative policy level. Despite the financial crisis of 2008 prompted, many interventions require deeper state of the economy; policy debates revolve around quantitative however.

Particular case is the sovereign debt crisis in Europe. On one side are the militants of fiscal discipline, such as the Ministries of Finance leaders of countries like Germany and the Netherlands, which require restriction of expenditures, despite the cost and economic and social consequences.

On the other side are Keynes sunshine set, to develop the argument that fiscal crisis can only be solved by economic growth, which in times achieved precisely by maintaining high levels of public spending, not reduce them drastically. In each case, the argument is not about the fundamental transformation of the economic structure. Nevertheless, to manage the situation through macroeconomic instruments that possesses state: tax policy, public expenditure policy and monetary policy.

In these examples, the economic structure is complex and relatively autonomous policy and structural changes in the state can intervene only at the margins.

In the case of developing countries, economic development problem arises in very different form. Although the developing countries (like the Kosovo) have in hand macroeconomic instruments (such as fiscal policy or budget), basic economic problems of developing countries are not cyclical in nature, but structural. In other words, the response of the state should be oriented towards structural transformation of the economy, to orient it towards creating surplus and increase the rate of accumulation and, consequently, economic growth in general.

In short, state policies should be structural, such that the fundamental aim of transforming the country's economic composition.

The difference can be described in this way. If you are a country whose economy produces one million cars, while you as a government with fiscal incentives (e.g. tax breaks) aims to foster investment firms to ensure that they produce 1.2 million automobiles, this is management macroeconomic growth through quantitative policy. Structural policies, meanwhile, aims to create an automotive industry where it does not exist.

In Kosovo, the current political circumstances, and in the current political and ideological configuration, a move towards state development seems unlikely. However, this does not prevent the elaboration of a developmental state opposition and alternative political project against what is unquestionably a totally failed economic model applied by the current government. And, again, it should be noted that there is no single formula developmental state. However, and this is the main conclusion of this brief treatment, state developmental challenges us to rethink and rediscover the art of statehood (statecraft), before falling into the trap of preoccupation with economic problems existing in economic discourse, or, expressed differently, the seek and provide quantitative solutions to problems that are structural.

\section{Conclusion and Recommendations}

\subsection{Conclusions}

This study shows the impact of fiscal policy on economic development of a country. We can say that fiscal policy (tax) which relate directly to the Tax Administration of Kosovo proved very successful especially in the value-added tax from the tax, which carried about $50 \%$ of overall revenues. VAT is continuously growing revenue. From this, we can understand that it is doing a good job in the field of awareness on taxpayers, but much remains to be done. Additional training should be organized for staff of TAK (Tax Administration of Kosovo). Especially in the construction and trade with imports because of the VAT credit to many businesses, that are in credit and no request to reimburse businesses for this part of Customs duty paid in the country or even within, then conclude that credit may be irregular because it does not apply for refund. However, the tax administration does not undertake concrete steps to verify if these businesses are able creditworthiness. Nevertheless, what leaves much to be desired, and that is worth mentioning is corporation tax, any tax on realized about $22 \%$ of revenue, and it is disturbing that the majority of businesses declare annual loss statements. Therefore, the Ministry of Finance should change the law and the legal right of loss carried forward for seven (7) years to cut in 2 or 3 years, because I think that will give results in direct revenue. 


\subsection{Recommendations}

\subsubsection{Recommendation 1}

Manager's decision on Kosovo should start doing escalation of VAT for things such as food, oil, bread, flour, sugar, salt, etc. So everyday household baskets. State intervention in the flow economy through fiscal policy is justified by regulations made in terms of eliminating the phenomena that impede the preservation of the general welfare of society.

Caution however, increase or a decrease in tax rates for taxes opportunities but also pose risks. Lower taxes can stimulate business and, when conditions are suitable, increase budget revenues. However, if you sit a lot, they can be harmful to budget revenues and could endanger public goods such as infrastructure, education and health care, etc.

Some arguments have shown that efforts to make things change in the tax system were more successful those that modify specific provisions.

Seeing these theories and many different theories of thinkers can conclude that any tax reform should be calculated taking good advantages and disadvantages, difficulties that in itself carries every tax reform and determination required in law enforcement.

\subsubsection{Recommendation 2}

Like the second recommendation concerns the privatization of state-owned enterprises.

The successfully develop the privatization process should be ensured: the development of its public (transparent), to avoid possible misuse what, sale of assets under the market price of what cannot offset the negative effects.

Where I think privatization in Kosovo should be developed based on competitive programs (manufacturing or commercial) and the open market. Important role played by the information, which creates conditions for massive participation of subjects in the privatization process and reduces the chances of double standards. Maximizing the cost approach is very important principle, because it means the elimination of privileges and buyers, enabling free and fair competition for all participants and promotes the interest of as many buyers.

\section{References}

Rosen,H.(2003) "Financat Publike" Publisher, McGraw-Hill, translated by printing house, Albin Tirana 2003.f.4-9.

Komoni,S(2008) "Financat Publike "Publisher printing house of the Economics Department of the University of Prishtina, Faculty of Economics, Pristina, p 35. 129-142. Bedri,S(2006)"Globalizimi-Tranzicioni dhe integrimet" Publisher, Albanica and Zenith, Ljubljana Pristina, p.15,145,146,163.

Panariti,S (2009)"Menaxhim projekti" Publisher, Adel, Tirana, p.161.

Nimani ,A(2010) "Politikat Finaciare"( With regard Kosovo), Publisher, University College-Business \& ISRN, Pristina, p.44-50.

Civici,A(2010)"Globalizimi ... Ante Portas": Issue II UET / PRESS. Tirana. p.100,101.

Ketri,N(2008) "Ekonomia Politike"Botues, Ufo press , Tirana ,p179,181.

Limani,M(2008) "Integrimet Ekonomike Evropiane" Publisher Universum University Prsihtinë, p.17-18..

Selmanaj,S(2006)"Globalizimi dhe Tranzicioni" Publisher, University College-Business \& ISRN, Pristina, p.,53-57.

Gazmend,L(2007)"Financat e Korporatave" Publisher,Dukagjini,Prishtina.p.120-123.

Brajshori,B(2010) "Menaxhimi i shpenzimeve publike dhe i proceseve buxhetore", Publisher, Fama College, Prishtina ,p.19.

Naryanan.M\& Vikran K. Nanda(1971)"Financije za stratesko adlicivanje" p.213.

03/L222 Law (2011) Issue II, Publisher, Tax Administration and Procedures, Pristina, p.16-203.

03/L- Law No. 161 (2011) Law on Personal Income Tax, publisher Tax Administration of Kosovo, Pristina, f403-488.

"Law No. 03/L-146" (2011) For tax http://econpapers.repec.org/RePEc:wpa:wuwppe:0505013 By Florije Govori; Politika FiskaleObjektivat,instrumentet dhe efektet 